\title{
Abstracts of papers read at the Annual Scientific Meeting of the Inter- national Medical Society of Paraplegia held on 26th and 27th July 1963 at Stoke Mandeville Hospital, Aylesbury, Gt. Britain.
}

\section{VESICO-URETERIC REFLUX IN GENERAL MEDICINE}

\author{
By Prof. M. L. RosenheiM \\ University College Hospital, London
}

CHRONIC pyelonephritis is now recognised as the commonest cause of the syndrome of hypertension and renal failure. Diagnosis is of ten delayed or difficult for the disease may present in many different ways. It may be active, latent or healed. The patient may present with recurrent urinary infection, with hypertension, with proteinuria or with any of the numerous manifestations of urinary infection. Chronic pyelonephritis may be unilateral and nephrectomy may occasionally relieve severe hypertension.

It has, in the past, been customary to classify chronic pyelonephritis into obstructive and non-obstructive. In the former some underlying cause of obstruction to flow in the urinary tract has been demonstrable and has been regarded as predisposing to renal infection. In the non-obstructive, or atrophic chronic pyelonephritis, no such underlying cause has been detectable.

The recent recognition that vesico-ureteric reflux can be demonstrated in a high percentage of patients with chronic pyelonephritis is thus of great importance. It has, of course, long been recognised that such reflux occurred in patients with neurogenic bladders, with urethral valves or with prostatic obstruction, but it is only in the past few years that reflux has been demonstrated in patients with simple atrophic chronic pyelonephritis.

Kjellberg and his colleagues in 1957 reported that reflux had been found in 34 per cent. of a large series of children with urinary tract infection with no demonstrable obstructive lesion. At University College Hospital, Edwards has demonstrated reflux in 76 per cent. of 55 patients with radiological evidence of chronic pyelonephritis. Over a period of four years, 36 patients with apparent primary chronic pyelonephritis have been under the care of the Medical Unit and in 23 (64 per cent.) vesico-ureteric reflux has been demonstrated.

There is much debate at the present time concerning the significance of this observation. Vesico-ureteric reflux would appear not to occur in the normal urinary tract, though it is not easy to collect control series.

Does reflux precede infection or is it the result of infection? This is the really important issue and is one that has, for many years, concerned those dealing with the paraplegic bladder. If reflux precedes infection, it must be presumed to act as an obstructive factor predisposing to the occurrence and establishment of infection. This view entails a belief in either minor degrees of bladder neck obstruction or of some intrinsic abnormality of the intravesical part of the ureter and holds out the hope that the relief of reflux might prevent the progress of chronic pyelonephritis.

On the other hand, there is evidence that reflux is not constant and may disappear with the cure of urinary infection. If this is so, surgical treatment may be misplaced, though it is possible that recurrent urinary infection ultimately leads to 
permanent laxity of the vesico-ureteric sphincter, leading to a vicious cycle that ends with the atrophic pyelonephritic kidney.

It is certain that chronic pyelonephritis commonly starts in childhood and reflux has been shown to be very common in young children with urinary infection. It is vital to try to determine whether the relief of reflux in childhood will prevent the later development of chronic pyelonephritis. The treatment of reflux is, at the present time, also under discussion. If surgery is contemplated, it would appear that ureteroplasty alone will not relieve reflux and that plastic widening of the bladder neck is also necessary. Pressure and flow studies during micturition are likely to throw light on the underlying mechanism of reflux and may help in defining the correct treatment.

\title{
AN EXPERIMENTAL INVESTIGATION OF VESICO-URETERIC REFLUX
}

\author{
By John E. S. ScotT \\ Department of Surgery, The Medical School, King's College, Newcastle upon Tyne, \\ Great Britain
}

EXPERIMENTAL work on vesico-ureteric reflux has been designed to answer two questions.

I. Does reflux occur as a primary phenomenon and predispose to infection in the urinary tract?

2. What are the factors which are responsible for reflux? The work falls into three phases.

I. The normal urinary tract.

Ureteric peristaltic studies showed that the ureter responded to rising intravesical pressure by increased peristaltic amplitude and frequency.

Following transvesical resection of the ureteric mucosal flap valve, the ureter responded to increased intravesical pressure in the same manner as preoperatively and reflux did not occur.

When ureteric peristalsis was abolished by sacrificing the dog, reflux took place.

2. The effect of prolonged reflux on the upper urinary tract.

Dogs in which the ureteric flap valves had been resected bilaterally were maintained alive for from 19 months to two years.

They all remained in good health and did not develop urinary infection or evidence of renal failure.

Reflux became visible radiologically in one or both ureters in all dogs from three to four months postoperatively.

Cine-cystography showed that peristaltic activity was depressed in those ureters which had free reflux.

Ureteric peristaltic studies were performed in the same manner as phase I as terminal experiments. These demonstrated that in all ureters where reflux was present, peristaltic activity was grossly depressed. The ureteric response to raised 
intravesical pressure was similarly depressed, or completely absent and free reflux occurred.

Post mortem histological studies of the kidneys were carried out. These revealed no evidence of acute or chronic inflammatory changes in the kidney.

3. Urinary infection and reflux.

These experiments are not complete and no results are available.

Reflux has been produced unilaterally by resecting one ureteric mucosal valve.

Organisms have been injected into the bladders of these dogs but so far a urinary infection has been successfully induced in only one out of four dogs. It is planned to study the effect of introducing organisms by the intravenous route and compare any changes that may occur on the refluxing and non-refluxing sides.

\title{
SUMMARY
}

In the dog, vesico-ureteric reflux may be induced by resecting the ureteric mucosal flap valve.

Ureteric peristalsis prevents such reflux from occurring so long as it retains its normal efficiency and response to raised intravesical pressure.

After a prolonged ureteric peristalsis becomes grossly deranged with loss of its normal response to raised intravesical pressure so that reflux occurs.

Prolonged reflux, in these dogs, did not lead to urinary tract infection or pyelonephritis.

\section{REFERENCES}

Scott, J. E. S., \& De Luca, F. G. (I96oa). Brit. F. Urol., 32, 2 I6. Scott, J. E. S., \& DE LuCA, F. G. (I96ob). Brit. F. Urol., 32, 320. Scott, J. E. S. (I962). Proc. R. Soc. Med., 55, 422.

ScotT, J. E. S. Accepted for publication. Brit. F. Urol.

\section{A FEW ASPECTS OF VESICO URETERIC REFLUX IN PARAPLEGIA}

\author{
By M. Maury, J. Cukier and L. Baccialone \\ Fontainbleau, France
}

I. Detection of Reflux. Reflux can be produced by a too rapid filling of the bladder or even by the presence of a catheter. The best examination to show a reflux is a slow cystogram, i.e. the incomplete filling of the bladder, I20 drips per minute with X-rays taken at every 50 millilitres, withdrawal of the catheter and followed half an hour later by pictures taken before and after micturition. The amount of dye to introduce is at the average I50 to 200 millilitres, being calculated according to the bladder capacity and the average diuresis.

2. Percentage of Reflux. The percentage of reflux (I I per cent. in our I960 statistics of 272 patients) is only of relative significance. Theoretically, cystograms should be done on each patient and repeated during each yearly check-up, which, 
however, would be contrary to the interest of the patients. It would also be a good thing to standardise the cystographic examination. Lastly it is usually said that reflux is much more frequent in automatic bladders than in autonomous ones, but do we really agree on the definition of these types of bladder, and do we know the proportion of each type in spinal cord injuries?

3. Treatment. Following Talbot we treated only:

I. reflux which has an effect on the morphology and the function of the kidney.

2. reflux which is the cause of frequent urinary flare-ups.

The other types of reflux need only to be watched regularly by cytobacteriological examinations and urographies (the study of the ureteric motor function with the radio-cinematographic technique would be of great interest). A good bladder function does not exclude the possibility of reflux with complications. The treatment of reflux varies according to its different degrees. It starts with the elimination of the factors favouring its development such as infection, lithiasis or suprapubic cystostomy (unless the bladder is too contracted). The antispasmodic agents acting on the fibres (Tetracaine, Banthine) could be useful to diminish the spasticity. Lastly, in reflux which is only present when voiding, it is sometimes necessary to diminish the sphincterian resistance by resection of the bladder-neck or infiltration or neurectomy of the pudendal nerve.

Drainage by an indwelling catheter for two to four months can make the reflux disappear, at least some of them. It is particularly indicated when there are diverticula or trabeculation in the bladder. With this treatment is usually associated a daily instillation of silver nitrate with a local anaesthetic. This treatment appears contra-indicated, when at the cystogram, the reflux disappears once the indwelling catheter has been removed.

When all the other treatments have been unsuccessful, plastic interventions such as advocated by Hutch and Bischoff could be tried provided the bladder is not too contracted or too many diverticula are present.

If these interventions are impossible, or are not successful, it may be necessary to save the kidney by using an indwelling catheter or performing even a cystostomy, or, by a cutaneous ureterostomy, entero-cystoplasty or even a cutaneous transintestinal ureterostomy (Bricker).

A partial or total vesico-sphincterian denervation by rhizotomy, sacral neurectomy or intrathecal alcoholisation could ameliorate certain types of reflux but on the other hand could also produce some, and it seems impossible, actually to define their indications.

4. Pathogeny. The cases of reflux which we have studied do not allow us to know the determining factors. Reflux being rare in neurologically normal subjects it is logical to think that the neurological factor is playing an important role, even indirectly, and it is likely that any damage or irritation of a neurogenic bladder augments the chances of reflux (with this idea in mind one must avoid any useless examination). Amongst all the possible damaging agents, infection seems to be the prevalent one.

Lastly, the anatomical modifications of the bladder and vesico-ureteric orifices, which often accompany the reflux, are possibly only secondary to the infection or to the neurological status of the bladder or both together. 


\title{
OBSERVATIONS ON THE AETIOLOGY OF VESICO-URETERIC REFLUX
}

\author{
By L. GutTManN \\ National Spinal Injuries Centre, Stoke Mandeville Hospital, Aylesbury, Bucks, Gt. Britain
}

THIS report is based on a material of 343 patients with complete and incomplete lesions of the spinal cord at various levels, in whom 5I 2 cystographic studies were carried out. Over 300 patients were examined during the last two years, amongst them 122 in the early stages following injury or disease of the spinal cord. In numerous cases, cystography was repeated several times. The standard technique adopted was to have the first X-ray film carried out after filling the bladder when the patient was relaxed (resting film), followed by a film taken during raised bladder pressure by straining either voluntarily or passively or due to reflex action (micturating film).

Reflux was found in 75 out of 343 cases ( 22 per cent.). In analysing these results there were 22I upper motor neurone lesions with more or less marked spasticity, with an incidence of reflux in 43 cases (I9 per cent.). One hundred and twenty-two cases were lower motor neurone lesions with flaccidity; amongst them, 32 cases ( 26 per cent.) had reflux.

In order to give a detailed analysis of the incidence of reflux in relation to level and degree of the cord lesion, the material was divided into cervicals (73), TI-5 (47), T6-I2 (89), and below TI2 (12) lesions. In all groups, a distinction was made between complete and incomplete lesions. It was found that in 120 patients with lesions at and above $\mathrm{T}_{5}$, including the cervicals, reflux was present in $2 \mathrm{I}$ cases ( 17.5 per cent.), while in IOI lesions at T6 and below, the incidence of reflux was 22 (22 per cent.). These findings confirm my previous views published in 1953 in 'Volume, Surgery of the British Medical History of World War II' that there is no evidence to assume a neurogenic factor as the direct aetiological factor of vesicoureteric reflux, as far as type, level and degree of cord lesion are concerned. On the other hand, Comarr and Bors (1955) and Damanski and Gibbon (1960) found reflux more frequently in upper motor neurone than in lower motor neurone lesions. Bors suggested that the preservation of the sympathetic innervation of the trigone in low cord lesions has some protective effect upon the ureteric orifice which accounts for the low incidence of ureteric reflux in lower motor neurone lesions. Damanski and Gibbon found reflux much more common in high than in low cord lesions. These authors divided their cases into those above T9, T9-I I and below TII. From a neuro-physiological standpoint this classification is not a satisfactory one, for it must be remembered that lesions at $\mathrm{T}_{9}$ and even above $\mathrm{T}_{9}$ may not only be transverse lesions but, as a result of haematomyelia or spinal artery thrombosis, also longitudinal ones, thus rendering an upper motor neurone lesion into a lower motor neurone lesion. Moreover, if one wants to assess the importance of sympathetic innervation on the incidence of reflux, as Bors and Comarr have done, one has to distinguish between cord lesions at and above $\mathrm{T}_{5}$, where the whole splanchnic control is crippled, and those lesions of lower segments of the cord below T6. The view that the cord lesion itself has a direct effect on the incidence of reflux has led several authors to carry out neurosurgical procedures, such as 
pudendal neurectomy, sacral neurectomy, anterior rhizotomy and posterior rhizotomy, as well as alcohol block. There is, however, no proof whatsoever that these operations had any significant effect on the reflux.

It has been suggested that change of bladder shape and in particular diverticulosis and contracture play an important part in the aetiology of reflux. I agree with this view with reference to the contracted bladder following long-standing suprapubic or urethral drainage, where either unilateral or bilateral reflux is found to be not uncommon. On the other hand, it must be admitted that reflux may occur in bladders of any shape or capacity.

Ever since Samson in I 903 published a paper 'Ascending renal infection with special reference to the reflux of urine from the bladder as aetiological factor in its causation and maintenance', this problem has been discussed by many authors. In accordance with other authors, I have come to the conclusion that infection of the bladder plays a very important aetiological role in the development of vesicoureteric reflux in causing impairment or destruction of the elasticity and valve-like action of the ureteric orifices, as a result of ureteritis and peri-ureteritis following bladder infection.

In this connection, it is worthwhile mentioning that of the 122 patients who had a cystogram within the first 12 months, the urine in 37 patients was sterile and none had a reflux, and of the 85 patients with infected urine only two had reflux. This indicates that reflux is as a rule a late development in paraplegics and tetraplegics, where ascending infection of the urinary tract plays an important part.

\title{
VESICO-URETERIC REFLUX
}

\author{
By J. Cosbie Ross \\ Liverpool, Great Britain
}

Mr. Cosbie Ross first discussed the two important aetiological factors in the causation of ureteric reflux, i.e. urinary infection and obstruction at either the bladder neck or external sphincter level. At the same time he mentioned the possible third neurogenic factor. He pointed out that although the most useful diagnostic measure was the cysto-urethrogram, it was of ten possible to demonstrate reflux by means of the isotope-renogram in which a 'humping' of the recording during the excretory phase was characteristic.

If the reflux is progressive, is stage III and beginning to endanger renal function, it is necessary to eliminate any obstructive factor at the bladder neck or at the external sphincter level. The means available for this include perurethral resection of the bladder neck, division of the external sphincter, subarachnoid alcohol block and pudendal neurectomy. As a corollary, he suggested that a lowering of the resistance to voiding may prevent or limit reflux during micturition and thus minimise the ill-effects on the upper urinary tract.

Mr. Cosbie Ross summarised the treatment by advising:-

I. The use of prolonged chemotherapy in mild cases of reflux, especially in stages I and II.

2. Any obstructive factor must be eliminated and may well clear up the reflux. 
3. At the present time the various plastic operations on the lower end of the ureter should be approached with caution. If operation is indisputably indicated, that advised by Paquin is probably the best.

4. In severe, progressive ureteric reflux with gross infection and renal failure, a diversionary operation, using a segregated ileal or colonic loop, may be necessary and a life-saving procedure.

\title{
VESICOURETERAL REFLUX IN PARAPLEGIA
}

\section{A CLINICAL STUDY}

\author{
By M. DAMANSKi
}

Liverpool Regional Paraplegic Centre, Promenade Hospital, Southport, Great Britain

I. Vesicoureteral reflux is frequent in paraplegia.

2. Cysto-urethrography, using a syringe is the most suitable method of investigation in paraplegia where it may not be possible to micturate when required to do so.

3. Whatever the possible neurological factor may be in the production of reflux, the main cause is infection.

4. Using special methods to combat cross-infection it has been possible to reduce the incidence of reflux in paraplegia from 31.5 per cent. to 7.5 per cent. If patients with paraplegia were admitted to special centres immediately after the spinal injury, it is possible that reflux might be largely eliminated.

\section{STUDY ON THE VESICO-URETERAL REFLUX BY CINE-RADIOGRAPHY}

\author{
By A. Rossier \\ Zürich, Switzerland
}

As our previous cineradiographic studies were carried out in collaboration with Dr. Maranta and Dr. Wirth from the Radiological Institute of Zürich University, our two observations reported here were made with the following material and technique: camera Arriflex, image intensifier Phillips I $3 \mathrm{~cm}$., film $36 \mathrm{~mm}$., I6 pictures/ sec. Cystometric studies were done at the same time in order to correlate the X-ray findings with the bladder filling and with the detrusor activity (Rossier and Maranta, I96I).

The first film applies to an eleven years old spina bifida girl with an operated myelo-meningocele, with a lower motor neurone bladder (LMNB). Reflux of the distal third of the left ureter appeared with a bladder filling of $50 \mathrm{cc}$. (intravesical pressure: about $6 \mathrm{~cm} . \mathrm{H}_{2} \mathrm{O}$ ) and reached the kidney pelvis with I00 cc. (pressure: about $8 \mathrm{~cm} . \mathrm{H}_{2} \mathrm{O}$ ).

The second film concerns a 27 years old spastic traumatic paraplegic patient with an incomplete $\mathrm{T}_{7-8}$ and complete $\mathrm{LI}_{\mathrm{I}-\mathrm{L}_{2}}$ lesion, and an upper motor neurone 
bladder (UMNB). Reflux of the distal third of the right ureter appeared with a bladder filling of $\mathrm{I} 5 \mathrm{cc}$. and reached the kidney pelvis with $50 \mathrm{cc}$., with an unchanged intravesical pressure of $2 \mathrm{~cm} . \mathrm{H}_{2} \mathrm{O}$; at this point, however, a reflux started to appear in the left ureter.

The analysis of these findings leads to the following conclusions:

I. Antiperistaltic waves may be found in ureters of UMNB as well as in ureters of LMNB.

2. A high intravesical pressure is not necessary to produce a reflux; it seems that antiperistaltic waves would account for a ureteral filling which takes place at a pressure lower than the hydrostatic pressure needed for raising urine from the bladder to the kidney (Hinman et al., I962).

3. Therefore, the conversion of a UMNB into a $\mathrm{LMNB}$, as recommended by Bunts (1957, 1959), will not necessarily suppress a reflux.

4. The fact that the entire ureter is visible for prolonged periods of time may be explained by a lack of peristalsis; moreover, the larger the ureter, the less the peristalsis.

5. Isoperistaltic waves moving downward and at the same time propelling dye upward reveal the inefficiency of the peristalsis because of the incomplete closure of the segment of the ureter following the 'bolus' of urine.

6. The momentary stop of some refluxes at the level of the middle and lower third of the ureter would confirm Fuchs' and Begg's theories of ureteral cystoids, quoted by Fey et al. (1957) and Noix (1959) and which, according to them, would represent a ureteral self-defense mechanism.

\section{REFERENCES}

Bunts, R. C. (1957). Trans. Amer. Ass. gen.-urin. Surg., 49, 199.

Bunts, R. C. (I959). F. Urol., 81, 720.

Fey, B., Truchot, P., \& NoIX, M. (I957). F. Radiol. 'Electrol., 38, 449.

Hinman, F., Jr., Miller, E. R., Hutch, J. A., Gainey, M. D., CoX, C. E., Goodfriend, R. B., \& MARSHALl, S. (I962). F. Urol., 88, 758.

Norx, M. (1959). Bull. Soc. Méd. Paris, 12, I.

Rossier, A., \& Maranta, E. (I961). Helv. Chir. Acta, 28, 758.

Dr. W. Gregoir and Dr. G. van Regemorter (Belgium) showed two films:-(a) Plastic Operation on vesico-ureteric reflux, $(b)$ Bladder replacement by intestinoplasty.

No abstract submitted.

\section{General Discussion on Vesico-Ureteric Reflux}

Rosenheim, M. L. (England) thanked Mr. Cosbie Ross for his comprehensive paper, which clearly showed the complexities of the problem. But, from the other speakers, it would appear that infection played an important part in the aetiology of reflux.

$H a r d y, A$. G. (England) said that, in his experience, the intrathecal alcohol block used for the abolition of spasticity in the spastic bladder may improve or abolish reflux, but this can return. He also made the observation that some patients have reflux for many years, and he quoted a patient who had had a reflux for 17 years without harmful effects. He had seen bilateral reflux occurring and recurring and resolving itself. He was troubled by some of the plastic procedures and had heard Mr. Cosbie Ross say that there was a stage when the bladder trabeculations and irregularities were such that they were past the 
point of repair. He felt that one had to do something before that stage was reached, but the difficult question was - at what point should one take action? With regard to infection, he came to the conclusion that although infection is an important factor it is not the only one.

Silver, $\mathcal{F}$. (England) drew attention to Lapides' studies on blocking the nerve supply of the ureter in non-paraplegic subjects by various means. He found that the nerve supply has little influence upon the phenomenon of reflux.

Hardy, A. G. (England) accepted the fact that the ureter could manage without any nerve supply at all, being a smooth muscle, but did not accept that the vesico-ureteric junction acted without neurological control.

Guttmann, L. (England) said there had been abundant proof that experienced neurosurgeons had done operations on various parts of the peripheral and central nervous system but they had come to the conclusion that this had no bearing whatsoever on reflux. With regard to the effect of intrathecal alcohol block, which he had introduced in I946, he would, of course, have been very happy to confirm Dr. Maury's findings that alcohol block might abolish reflux, but his experience was that while in some cases reflux may disappear in others it has appeared after alcohol block.

Frankel, $H$. (England) pointed out that Dr. Damanski's figures showed that there was a higher incidence of reflux amongst patients with higher spinal cord lesions, which, however, showed great reduction when he was able to control urinary infection. Did Dr. Damanski still find some differentiafion amongst his less infected patients?

Damanski, $M$. (England) replied that, although he had been successful in controlling urinary infection in the early post-traumatic period, there were too few patients with reflux to answer this question properly, but the higher incidence of reflux in the upper motor neurone lesion still persisted. Patients with low lesions suffered for a short time with complete retention of urine and the period of bladder training was shorter than in high lesions. The necessity for indwelling catheter might contribute to vesico-ureteric reflux.

Walsh, F.F. (England) expressed surprise to hear from Dr. Damanski that the period of bladder training was shorter in low lesions. This was not the experience of the National Spinal Injuries Centre, where automatic bladder developed sooner in high lesions than in low lesions, with consequent earlier micturition, especially in young people.

Damanski, M. (England) replied that he had been referring to very low lesions in whom the abdominal muscles were not paralysed.

Gibbon, N. (England) commenting upon his and Damanski's classification above T9, T9-I I and below TII, said that this was an arbitrary division and not intended to be related to bladder innervation at all, but the higher the lesion the greater the incidence of reflux. This did not appear to be related to the type of bladder function, ureteric deformity or external pressure. Dr. Damanski's recent figures showed that upper motor neurone cases seemed to have a higher incidence than did the others.

Dr. Hardy had asked what and when something should be done with regard to reflux. One had to distinguish what grade of reflux was present. If it were grade I, Dr. Hardy would agree that this was no indication for any specific treatment directed against the reflux. Where reflux was associated with increasing dilatation of the upper urinary tract and associated with clinical signs of pyelonephritis and trabeculation and with high residual urine and urinary infection, the infection should be eliminated as a first step and the vesico-ureteric orifice ignored. When it had been shown that the bladder wall was reasonably normal, elimination of infected residual urine would of ten eliminate the reflux. A practical point mentioned by Dr. Hardy was that if a patient had a reflux it was obviously better to empty the bladder by abdominal straining rather than by manual compression, as the latter pushed the urine up into the kidneys and was obviously more harmful.

Guttmann, L. (England) referring to the classifications made by Dr. Damanski and Mr. Gibbon, said he had thought that these must have been arbitrary, which was why he had drawn attention to this in his paper. If they accepted the views of Dr. Bors and Dr. 
Comarr about the influence of the sympathetic control on the incidence of reflux, surely the cases had to be divided into those above $\mathrm{T}_{5}$ and those below $\mathrm{T}_{5}$.

$S c o t t, \mathcal{F}$. E. S. (England) referred to urological conditions in children with enuresis without infection. He had been surprised to find that, although there was no history of infection, these children had ureteric reflux. He had followed up these cases for one or two years and found that they developed a urinary infection in time. Other children had an infection for a short time only, which was treated and lasted no longer than a week or Io days. It would be difficult to find out whether this short infection influenced vesicoureteric mechanisms. However, they had reflux and it might be that this was due to a congenital anomaly at the vesico-ureteric junction which might predispose infection. In paraplegics, however, there was a fundamental pattern in the dynamics of the bladder and urinary infection might well ensue, which if severe would surely produce marked changes in the ureteric orifices. This tie-up with the urinary infection could rapidly affect normal ureteric peristalsis. This, in his opinion, was one reason why reflux appeared at one time and disappeared at another.

Damanski, $M$. (England) in referring to Dr. Rossier's paper, discussed the question of residual urine in patients with reflux and pointed out that the absence of residual urine in such a case did not give a true picture, as the 'residual' urine had, in fact, been pushed upwards into the ureter and kidney. Dr. Rossier's film had contributed to a better understanding of the dynamics of reflux.

Zachary, R. B. (England) discussed the question of reflux in paraplegia with spina bifida and suggested that the two elements, infection and obstruction, could play a part either individually or as a combination. In some of the newborn, reflux and even hydronephrosis was found within the first few days for no apparent reason.

Guttmann, L. (England) recalled that some American authors had also found reflux in new-born babies. They came to the conclusion that this was due to congenital abnormalities but on the other hand they had suggested that this might be due to a pyelitis occurring in utero. Had Mr. Zachary made any observations on this point, and in particular had there been any special pathology, such as maldevelopment at the vesicoureteric junction, in those babies who died.

Zachary, R. B. (England) replied that no infection was found but no special investigations on the pathology were available so far.

\title{
THE SPINA BIFIDA PROBLEM SOME FUNDAMENTAL CONSIDERATIONS
}

\author{
By A. N. GuthKelCH \\ Royal Manchester Children's Hospital and Salford Royal Hospital, Great.Britain
}

SPINA Bifida Cystica is the commonest of all the major congenital malformations. Each year more than 2000 spina bifida babies are born in the British Isles and at the present rate of increase of our total population, and assuming that the frequency of the condition shows no sudden change, the annual number of new cases will rise to something like 2500 by the year 2000 . Twenty years ago a few cases of spina bifida cystica survived to the age of I year, but this is no longer the case. Even assuming an early mortality of 50 per cent., which is the present figure, and almost certainly capable of improvement, we shall soon have to budget for the survival of more than Iooo new cases a year. Moreover:

I. Myelocele (open myelomeningocele) is by far the commonest variety of spina bifida cystica. 
2. Of all cases of repaired myelocele at least a third according to the most optimistic forecast, and perhaps nearer a half, will be paraplegic.

3. Hydrocephalus can now be surgically controlled and the I.Q. of nonhydrocephalic spina bifida children is normally distributed. Assuming that by 1965 every live-born spina bifida baby is submitted to active treatment, then by I980 we shall have something like 5000 intelligent but paraplegic spina bifida children of school age.

We cannot avoid the challenge of such a problem. Others will speak of the management of spina bifida; the remainder of my remarks will be devoted to enquiring whether there is any hope of its prevention.

Although genetic factors may determine a special liability to one or another form of malformation of the C.N.S. in particular populations, it is unlikely that either anencephaly or spina bifida is subject to Mendelian inheritance. Both malformations have been recorded as occurring in one only of identical twins. There is an extra risk of both in respect of first births, and this risk may be influenced by the environment of the mother. There is also a considerably increased liability to malformations of the C.N.S. generally in all pregnancies later than the sixth. More than one writer has reported a well-marked seasonal variation in anencephalus births and sometimes a similar variation is found for spina bifida. In Scotland there is a higher incidence of spina bifida in the big towns than in rural districts, and there are considerable variations in the incidence of anencephaly from country to country.

Anencephalus and spina bifida should be regarded as two aspects of the same disorder, namely a faulty closure of the neural plate. Not only can this be shown by morphological studies but also the association between the two deformities in still-born pregnancies is 175 times higher than can be accounted for by chance alone. Finally it is well known that the Arnold-Chiari malformation (actually first described by Cleland) is almost invariably present in cases of myelocoele. Like both spina bifida itself and anencephaly, this malformation is the result of an overgrowth of the C.N.S. It is surely suggestive that these three have all been produced experimentally and it has been shown that to be effective the toxic substance must be administered just before the time of closure of the neural tube, which in humans is towards the end of the third week after conception. At least one such group of substances, namely the salicylate, is a common medicinal agent.

Is it dangerous for a woman to take aspirin during the first month of pregnancy and especially at about the date of the first missed period? What role is played by diet and by bacterial or virus infections?

If spina bifida is an acquired rather than a hereditary disorder it may be preventible. There is an urgent need for fundamental research and the figures given at the beginning of this paper show how rich a reward it could reap.

\title{
SPINA BIFIDA
}

\author{
By W. J. W. SHARRARD \\ Sheffield, Great Britain
}

THE primary concern of an orthopaedic surgeon in the management of spina bifida must be with the paralysis and deformity that results from it; but if any measure of 
success is to result from his treatment, he must, as in other conditions such as traumatic paraplegia, cerebral palsy and poliomyelitis, possess an adequate understanding of the neurological state underlying the paralysis and be prepared to work in very close liaison with his colleagues in paediatric surgery, neurosurgery, neurology and genito-urinary surgery. It is thanks to the combined efforts of a team of this sort at the Children's Hospital Sheffield that some new facts have been discovered and new lines of treatment evolved. Our total material includes over 700 cases of spina bifida cystica seen during the last eight years. This paper is particularly concerned with spina bifida cystica, of which by far the commonest variety is myelomeningocele.

Early Management. Before Io years ago, not more than 5 per cent. of children with myelomeningocele survived the first year of life. If they did not die of meningitis, they were likely to succumb later to hydrocephalus. Advances in neonatal surgery and anaesthesia, in antibiotic therapy and in the management of hydrocephalus by the Spitz Holter valve have completely altered the prognosis so that the survival rate at the end of the first year is now 60 per cent. or over. The paralytic aspects of the condition, previously a secondary consideration to the more fatal complications of meningitis and hydrocephalus, have now received much more attention. The early survivors among our cases showed a high incidence of complete paralysis of the lower limbs. So common was this, that it was regarded as almost a natural and expected consequence of myelomeningocele. However, a review (Sharrard, I962) of children treated between 1956 and I96I suggested that there was considerably less paralysis of the lower limbs in children treated by immediate emergency closure of the myelomeningocele sac than in those in whom conservative treatment or delayed closure had been undertaken. To determine whether early closure - that is within hours of birth-was liable to result in greater mortality, meningitis or hydrocephalus, a controlled trial was undertaken in 1962 between immediate surgery and conservative management or delayed surgery. The results showed less mortality, less meningitis and no change in the development of hydrocephalus. The results as regards paralysis were startling. None of the children treated conservatively showed any recovery of paralysis and some who had been almost normal at birth became completely paralysed and remained so permanently. None who were treated operatively showed any increase in paralysis and many showed considerable recovery after closure (Sharrard, Zachary, Lorber and Bruce, 1963). Since this time, emergency immediate closure has been the treatment of choice.

The pathological basis of the paralysis in myelomeningocele. Eighty infants have been examined neurologically at birth prior to closure of the spinal defect to determine their level of paralysis. Electrical stimulation and, in some cases, electro-myography of the muscles of the lower limbs has been done and biopsies have been taken of muscles representative of various segmental levels (Sharrard, I963). In addition, the neural plaque has been stimulated and activity in the lower limbs recorded. In eight out of Io cases, the peripheral innervation of the lower limbs has been normal to these tests or only the lowest sacral roots have been affected even when the muscles appeared to be paralysed on clinical examination. The lower limbs in these children have shown no deformity. In two out of Io cases, there has been partial paralysis of the lower limbs, often represented by a 
normal root supply from the lumbar segments and paralysis of the sacral segments. These children have invariably shown deformity at birth including paralytic dislocation of the hip, fixed extension deformity of the knee and calcaneovarus deformity of the feet. Provided that closure has been adequate and is uncomplicated by meningitis, a fair proportion of those showing normal lower limb innervation by electrical testing have shown recovery, sometimes to complete normality. Those showing partial innervation have never recovered more than the innervation shown to be present by electrical stimulation. Myelomeningocele can, therefore, be divided into two groups; one with potentially normal spinal cord and root function and the other with a myelodysplastic defect. To this must be added a small group in whom the lower motor neuron innervation can be shown to be intact but there is a defect in the spinal cord itself at a higher level resulting in a paraplegia of spastic type even though adequate closure has been performed.

Orthopaedic Management of the Paralysis and Deformity. The orthopaedic surgeon who undertakes the treatment of deformities in myelomeningocele must discard all his previous conception of the management of other types of congenital deformity. Treatment of the disclocated hip by methods appropriate to ordinary congenital dislocation of the hip are not only completely ineffective but may have disastrous results. All forms of traction, frames and splintage to obtain reduction are not advisable. The hip dislocation is a paralytic dislocation, the management of which must primarily be operative and directed to the shortening and imbalance of musculature in the region of the hip.

Hip dislocation, even if present at birth, should be left alone until management of the myelomeningocele sac and the immediate treatment of any concomitant hydrocephalus has been completed. Reduction of the dislocation may by then be attempted using open adductor tenotomy followed by splintage in abduction and extension. The full frog position should not be maintained constantly for more than six weeks or the hips will remain in that position permanently. Once reduction has been obtained, splintage can be used with care to maintain the reduction for a time varying between six months and two years but, inevitably, the hips will redislocate unless measures are taken to correct muscle imbalance. In these cases, the psoas and all other hip flexors, all the adductor muscles and the quadriceps are normally innervated whilst the gluteal muscles are completely or almost completely paralysed.

Transplantation of the iliopsoas tendon posteriorly through the ilium to the postero-lateral aspect of the greater trochanter corrects the imbalance, prevents the head from re-dislocating and, later, allows the child to walk without any hip splintage. In some cases, valgus of the neck of the femur may also require a varus osteotomy to be done. In a few cases, open adductor tenotomy and abduction of the hips does not result in reduction of the dislocation. In these, there is severe shortness of the iliopsoas and the hip will be found to be elevated and externally rotated. These patients need division of the iliopsoas tendon to obtain reduction, posterior transplantation of the tendon being done at the same time. This operation can be done, if need be, as early as 6 months of age. Fixed extension of the knee usually arises because of normal action in the quadriceps muscle in the presence of paralysis of the hamstring muscles (semimembranosus, semitendinosus and biceps femoris). If the knee does not mobilise spontaneously or there is congenital recurvatum, quadriceps-plasty will correct the deformity. 
The deformity of the foot is almost always a varus, calcaneo-cavus or calcaneus deformity. It is unwise to attempt to correct the deformity by the use of metal or similar types of splint. However carefully applied, sores are likely to develop. The deformity is best corrected by open division of the short tissues using a ' $\mathrm{V}$ ' ' $\mathrm{Y}$ ' incision on the inner side of the ankle and foot. When, as is of ten present, there is paralysis of all the musculature except for tibialis anterior, division of all structures except the posterior tibial nerves and vessels will correct the deformity and the tibialis anterior tendon can be transplanted laterally or posteriorly into the calf.

Calcaneus deformity is corrected by a similar but less difficult soft tissue division with transplantation of tibialis anterior and peroneus tertius to the calf. It is vital that a plantigrate foot be obtained before the child starts to walk. If this is done, sores will not develop in the feet; if it is not achieved, sores on the outer aspect of the sole of the foot are almost inevitable.

\title{
CONCLUSION
}

Advances in the management of myelomeningocele and hydrocephalus have, in recent years, resulted in a better prognosis of mortality and morbidity in spina bifida cystica. In some cases paralysis can now be avoided, in others, partial paralysis can be treated by appropriate orthopaedic measures and deformed limbs straightened. In future, it seems likely that only a few, probably io per cent. or less will be permanently paralysed. The remainder can be made capable of independent walking.

\section{REFERENCES}

Sharrard, W. J. W. (1962). Develop. Med. Child Neurol., 4, 3 IO.

Sharrard, W. J. W. (I963). Proc. R. Soc. Medi., 56, 5 IO

Sharrard, W. J. W., Zachary, R. B., LoRbers, J., \& BRUCE, A. M. (1963). Arch. Dis. Childh., 38, 18.

\section{SPINA BIFIDA OCCULTA AND SPINAL DERMOIDS}

\author{
By A. SuTCLIFfe KeRR \\ Liverpool, Great Britain
}

Although Kahn, in 'Correlative Neurosurgery' draws attention to the fact that spinal dermoids are not exactly rarities, their occurrence receives scant attention in standard text books of Neurology and even Elsberg in 'Tumours of the Spinal Cord' records only a single example.

Nowhere has attention been drawn to the association between these lesions and the concomitant presence of spina bifida occulta.

Ten cases of such an association have been encountered in the Liverpool Neurosurgical Service during the past I5 years, and five dermoids without spina bifida during the same period. The dermoid tumour is not necessarily at the same level as the bony lesion and in seven out of the Io cases, the only embryological layer involved was the ectoderm. The other three were teratomatous. 
In eight out of the ro cases, symptoms did not arise until the patient was over the age of 20 and a warning is given not to ascribe increasing neurological disabilities merely to spina bifida occulta nor to hypothetical bands tethering the spinal cord.

\title{
ABERRANT TISSUES IN SPINA BIFIDA
}

\author{
By L. P. Lassman and C. C. Michael James \\ Newcastle upon Tyne, Great Britain
}

IT is usually assumed in dealing with spina bifida aperta that there is primary dysplasia of the spinal cord. Warkany has shown in the rat that degeneration of neural tissue in the foetus complicates the picture of dysplasia of the spinal cord.

The eventual result is that at birth the spinal cord is incompletely formed and there are isolated areas of neural tissue around it in the sac of the myelomeningocele. Where there has been degeneration there will be attempt at repair and consequently we see gliosis, particularly in the subpial marginal nervous tissue. This gliosis will lead to strangulation of functioning tissues to some extent and will increase the amount of dysfunction.

The rationale of surgery is based on two concepts:

I. The closure of the wound to prevent infection.

2. The reduction of tension on neural tissues.

So far so good. This deals with the abnormality of the spinal cord itself. Because there has been delay in the formation of the spinal cord there is also delay in the formation of meninges, bones, muscles and skin. The embryonic tissues attempting to form these structures are frustrated and consequently are formed incompletely. Some of the embryonic tissues develop as aberrant structures which may be partly functional. Those which are not functional will become fibrous tissue and may well interfere with conduction of the normally formed neural tissues. They interfere by pressure or by fixation so that the spinal cord cannot ascend within the vertebral canal in the course of normal growth.

In the sac of a myelomeningocele therefore, there are two factors to consider:

I. The dysplasia of the spinal cord and the associated gliosis.

2. The fibrosis resulting from the aberrant tissues derived from mesoderm, neural crest cells and non-neural extoderm.

The first group is well-known and I do not propose to discuss it further.

During the last seven years, with my orthopaedic collaborator, Michael James, I have operated on 60 cases of spina bifida occulta which have had congenital anomalies affecting the spinal cord or cauda equina. The most common of these congenital anomalies are aberrant embryonic tissues resulting from foetal dysraphia, such as posterior nerve roots, which may continue to function or which may fail to develop properly and remain as bands of dense fibrous tissue. These same elements which are found in spina bifida occulta may well occur in spina bifida aperta, but because their existence is not commonly known they have not so far been positively identified, except that a septum in association with diastematomyelia may be found, 
even when operating on a baby soon after birth. In the surgical treatment of spina bifida aperta it is not sufficient only to close the sac, for the spinal cord and nervous elements must be released and any non-functioning aberrant tissues, which includes a bony or fibrous septum, must be removed. The reason for this is that these tissues are liable to fix the spinal cord and nerve roots, and later produce the types of neurological deficit which we have found in spina bifida occulta. Illustrative slides are shown.

In conclusion I would like to emphasise that spina bifida occulta and spina bifida aperta are both forms of spinal dysraphism. The lesions which occur in the lesser abnormality may well be found in the greater. Diastematomyelia is the best known of these and is commonly associated with a septum.

The other forms of aberrant tissues in spina bifida occulta may well be found in spina bifida aperta.

Improvement in cases of myelomeningocele operated on at birth is thought to be due to the progressive myelinisation of tracts and fibres, but improvement may also be associated with coincidental removal of extrinsic lesions.

\title{
FILM DEMONSTRATION OF TRAINING OF SPINA BIFIDA CHILDREN
}

\author{
A. Grossiord and Begzadlan-Katchatrian \\ Raymond Poincaré Hospital, Garches, France
}

THE film shows a few scenes of the motor rehabilitation of children afflicted with paralytic spina bifida. Three cases were shown which present different difficulties, and the film demonstrated the importance of an early motor rehabilitation in these cases as well as the painstaking measures which must be taken in the prevention of deformities. The aspects of the motor deficiences in cases of spina bifida are such that walking should practically always be possible, although support is of ten necessary. In one of the cases, it was seen that even with severe paralysis walking could be started before the age of 2 . The results are really good in those cases where the intellectual level of the child allows it. The very important question of the sphincters has not been mentioned in this film.

\section{GENERAL DISCUSSION ON SPINA BIFIDA}

Hancock, D. O. (England) said that this condition of a crippled child was particularly sad. The parents had to be handled very carefully and must be taken into full confidence; they must be given the true facts and the prognosis, as otherwise resentment very easily arose. He reported on 83 cases which had been observed in Bristol from 1957-1962. Sixtyfour were operated upon within one week of birth, I 6 died, nine from meningitis. Twentyone were operated upon later, six died, none of them from meningitis.

Sharrard, $W . \mathcal{F} . W$. (England) said they were very conscious of the dangers of meningitis following operation, but one had to consider a child which was paralysed with a paralysed bladder. Therefore, one had the problem of deciding what was the ultimate aim; IOo per cent. children who had no meningitis but were completely paralysed or a lesser percentage of children with at least a good chance of being normal, near normal or reconstructable. He would choose the latter, but it was indeed an ethical problem. 
Hancock, D. O. (England) agreed with Mr. Sharrard's views.

Sutcliffe Kerr, A. (England) expressed some apprehension about active interference in spina bifida children as immediate management. He questioned whether it was right to risk losing a large number of children through immediate operation and subjecting the half who survived to years of unhappiness with multiple orthopaedic, urological and neurosurgical operations. What, he asked, was the right answer? He did not feel that salvaging these children at the expense of a life-time of operations was in itself the answer.

Sharrard, $W . \mathcal{F} . W$. (England) said that the picture of the child in their clinics had changed out of all recognition, and he asked that no-one should make up his mind until he had seen the children in their clinics. Like children with cerebral palsy or thalidomide deformities, children with spina bifida could be salvaged.

Zachary, $R$. B. (England) thought that it had not yet been realized what could be done for these children later on. He reminded the audience of the fate of paraplegics I 5 or so years ago, since when Dr. Guttmann and other members of this Society had shown what could be done for them. Much could now be done to help these children, and it had been their experience that if a child died from meningitis after some time, the mother thanked them for doing what they could.

Guttmann, L. (England) felt that the truth lay somewhere in the middle, but he bowed to the experience of Mr. Sharrard and Mr. Zacchary, which was based on 700 patients. With their experience, they had changed the outlook for many of these children. His own experience was concerned mainly with adult spina bifida patients, and no doubt one could help these patients, although some of them were admitted in extremely neglected conditions. Some of these patients could be so rehabilitated as to become employable, and he referred to a boy who had been admitted at the age of 16 , was now 25 years old and employed full-time in a factory in London, living as a resident at the Duchess of Gloucester House.

He said, however, that there was one interesting psychological point in these adults. Their double incontinence did not worry them in the least, and they had not developed that sense of embarrassment and shame in this respect which the able-bodied develops from childhood after training. He felt that this should be an important part of the psychological training of these patients, as on this depended their social integration.

Guthkelch, $A$. N. (England), in discussing the complications of spina bifida, summarised two remaining problems:

I. Meningitis and its complications, and

2. Hydrocephalus and its complications.

They were now more or less in a position to control hydrocephalus. This left the problem of how to minimise the risk of meningitis, and they might be able to give the answer in about five years' time.

Harris, $P$. (Scotland) raised the question of associated abnormalities to the maldevelopment of the spinal cord in these patients, such as cardiac abnormalities and those of the alimentary tract. If treatment was to be carried out within 24 hours of birth, what screening could be done?

Sharrard, $W . \mathcal{F}$. $W$. (England) replied that there were two parts to this. The decision must be made quickly; some children were obviously suffering from cardiac or lung abnormalities, which made their lives very precarious as the chances of their dying anyway from other operations was very high. Some of these children had other abnormalities and it was surprising how of ten they got away with it, but these might, of course, kill them later. He did not think that a full screening was possible. The other point he mentioned was the prognosis of the paralysis. He felt that faradic stimulation might give an answer to the prognosis of the lower limbs. He thought that the chances were better when the meningocele was closed, and he said one would be surprised how of ten complete recovery occurred in the lower limbs in a child who appeared to be paralysed at birth. 


\title{
A NEW TECHNIQUE FOR THE USE OF PHENOL TO CONTROL SPACISTICITY AND SPASMS
}

\author{
By Phillip Harris and J. A. Simpson \\ Western General Hospital and Northern General Hospital, Edinburgh
}

IN this preliminary communication a technique was described by which an attempt is being made to selectively alter gamma-efferent fibre function using I 5 per cent. Phenol in Glycerol to abolish intractable spasticity and spasms in patients with spinal cord damage. The appropriate anterior spinal nerve roots are identified at laminectomy with the aid of electrical stimulation of the various exposed roots and continuous cystometrography (Mr. Jack Newsam).

The appropriate nerve roots involved in perpetuation of the intractable spasms are then carefully painted with the Phenol in Glycerol solution.

So far, one patient with a complete lesion at $\mathrm{D}_{4}$, and a second patient with a partial lesion at $\mathrm{D}_{4}$ have been treated, and two other patients with severe adductor spasms have been treated. The latter two patients had the obturator nerves painted with the Phenol in Glycerol solution, the former two patients had the anterior nerve roots painted. The aim is to abolish intractable spasticity and spasms without disturbing automatic bladder function and in incomplete lesions to abolish spasticity and spasms with minimal disturbance of residual motor and sensory functions.

It is hoped that this technique may have advantages over peripheral procedures on tendons, muscles and nerves, and on intrathecal Alcohol or Phenol in patients with intractable spasticity and spasms from spinal cord damage.

\section{DISCUSSION}

Sutcliffe-Kerr, A. (England) said that the effect of Phenol on the motor root would be an admirable one, if it could be achieved. If the alpha and beta fibres could be left intact, it would be useful particularly in disseminated sclerosis cases. Like Mr. Harris, he, too, was opposed to blunderbuss therapy with Phenol block, because of the damage to the bladder. When a man was stabilised with an automatic bladder, he would not want to be infected. In cases of paraplegia, with no motor function, he had no hesitation in suggesting anterior rhizotomy.

Damanski, M. (England) asked whether Phenol affected the autonomic nervous system and in particular the para-sympathetic fibres running as somatic fibres in anterior roots.

Hardy, A. G. (England) pointed out that he had had the opportunity of looking at some of the cords and roots of people who had died and in whom he had done Phenol and alcohol blocks some years previously. The neuro-pathologist found that the bundles of the roots of the cauda equina showed degeneration only on the outside of the bundles while the inside were apparently untouched. Because of return of spasticity following Phenol injections, he had reverted to doing peripheral destructive procedures.

Maury, M. (France) said that they used Phenol in lateral position. To make the action of the Phenol certain, it was injected at the level of LI-2 or L2-3 in order to touch the flexor groups. The solution was 50 per cent. glycerine and the amount varied from $\frac{1}{2}$ to $\frac{3}{4} \mathrm{cc}$.

Michaelis, L. S. (England) pleaded for careful, individualised use of peripheral operations in incomplete lesions with spasticity and he felt that laminectomy was not 
required in these cases. He had particularly good success with high division of the iliopsoas in severe flexor spasms and contractures of the hip. The term 'destructive', used by Dr. Hardy, was perhaps responsible for the low esteem in which these peripheral operations were held, as in fact they were constructive.

Guttmann, L. (England) thought that the confusion regarding the intrathecal Phenol injection was mainly due to the fact that the first advocates of this method made light of the effects on the bladder. At Stoke Mandeville, they had seen patients who had been admitted af ter these injections with most unfortunate results regarding the bladder function, which before the injection had been normal or satisfactory. He had stressed years ago that neither Alcohol nor Phenol should be used in incomplete lesions of the spinal cord with satisfactory bladder function. Dr. Michaelis had made it quite clear that, in such incomplete lesions, spasticity could be greatly controlled by selective operations on peripheral motor neurone either by resection of the nerves, in particular the obturator nerve in profound adductor spasms, by division of the iliopsoas in intractable flexor spasms of the hip, by resection of the inner hamstrings in flexor spasms of the legs and by elongation of the Achilles tendon with or without subcutaneous division of the long flexors of the toes, if the plantar flexors of the foot and toes were predominant in the spastic syndrome. $\mathrm{He}$ had abandoned laminectomies and rhizotomies for many years and was quite satisfied that the peripheral operations he had mentioned were not only adequate but the method of choice for these patients. In complete lesions with intractable spasticity, including uninhibited spastic bladder, he still preferred the intrathecal Alcohol block and could not find that Phenol had any advantage.

With regard to Mr. Harris's method, he felt that it was too early to make definite conclusions about the permanent effect of the method described, and he hoped that Mr. Harris would give them the benefit of a follow-up talk in a year or two's time. There might, however, be an indication to inject Alcohol, Phenol or even better Formalin into the spinal cord exposed at laminectomy in certain types of malignant, intramedullary tumours, to prevent further growth of the tumour.

Sutcliffe Kerr, $A$. (England) was rather unhappy about the suggestion to inject destroying chemicals in intramedullary tumours which could not be removed. He would rather prefer X-ray therapy, as some of these patients recovered function which would be lost following injection of alcohol, etc.

Guttmann, L. (England) thought he had probably not made himself clear. He had been referring to those patients with malignant, intramedullary tumours who had complete transverse spinal syndromes.

Sutcliffe Kerr, $A$. (England) referred to the question of bladder function following Phenol. He thought Mr. Harris would not mind his adding that on the slides which had been shown there were two types of bladder-in one the function was destroyed and in the other preserved. The one in which the bladder function was destroyed demonstrated how not to use Phenol by general injection, but in the two cases where the nerves had been selected at operation and painted with Phenol bladder function had been preserved.

\title{
THE OXYGEN COST OF BREATHING IN TETRAPLEGIC PATIENTS
}

\author{
J. R. SILVER \\ National Spinal Injuries Centre, Stoke Mandeville Hospital, Aylesbury, England
}

SEVERE muscular exercise in normal subjects produces profound reactions in the respiratory, cardiovascular, nervous and endocrine systems. There is an increase 
in the ventilation and the cardiac output, an accumulation of lactic acid and other metabolites in the active muscles, and a selective vasoconstriction of the blood vessels to the inactive muscles. If the exercise is severe enough profuse sweating and pyrexia occur.

In the tetraplegic subject many of these reactions are modified by the extensive paralysis of the body, particularly the interruption of the sympathetic nervous system. It is not known to what extent the tetraplegic patient can compensate for this paralysis or what limits the performance during exercise. In this study some of these problems are examined in detail.

Cournand has shown that in patients with severe cardiopulmonary disorders the oxygen consumption of the respiratory muscles is excessive and contributes to the patient's disability. Since tetraplegic patients maintain ventilation mainly with their diaphragms, this situation might also be operative, and thus limits the tetraplegic patient's ability to exercise.

The oxygen consumption of the respiratory muscles of Io tetraplegic patients was measured using the technique of E. J. M. Campbell, the principle of which was to measure the oxygen consumption of a subject at rest and at several levels of ventilation. The oxygen consumption was measured by recording the disappearance of oxygen from a closed circuit spirometer incorporating a motor blower and carbon dioxide absorber. Ventilation was increased by making the subject breathe through varying amounts of dead space provided by thick-walled rubber tubing. It was found that the patients could not increase their ventilation above 30 litres per minute due to the paralysis of their expiratory muscles. Expiration was achieved by the passive recoil of the elastic tissues of the lungs and chest wall.

At these levels the average oxygen consumption in all Io patients was $\mathrm{I} \cdot 5 \mathrm{ml}$. per litre of excess ventilation with a range of $.66 \mathrm{ml} .-2 \cdot 7 \mathrm{ml}$. in the individual patients. This compares with Cournand and Campbell's findings in normal subjects of $\mathrm{I} \mathrm{ml}$. and $\cdot 25 \mathrm{ml}$. and in patients with cardiopulmonary disorders of $25 \mathrm{ml}$. and $7 \mathrm{ml}$. at the same levels of ventilation.

It was concluded that the ventilatory capacity in tetraplegic patients was severely reduced but the oxygen consumption of the respiratory muscles was not excessive.

\section{DISCUSSION}

Hardy, A. G. (England) commenting upon Dr. Silver's figures, reported that he had had 23 tetraplegics during the year. One had had a capacity of only $450 \mathrm{cc}$. with only half of the diaphragm acting; half of his cases had had a capacity of more than Iooo. From a practical point of view, the ascertaining of the vital capacity in tetraplegic patients in the acute stages was of importance regarding indication for a tracheostomy. Some patients were admitted with associated injuries, where the injury to the lung was in the foreground of the clinical picture, and in such a case immediate tracheostomy was a life-saving measure.

Grossiord, $A$. (France) drew attention to the research he had undertaken with Mrs. Jaeger-Denavit concerning breathing problems in the paraplegic and tetraplegic patient. The ventilatory capacity, as one knew, was of ten reduced, especially in high lesions. Their work was based mostly on the figures of vital capacity and their variation in relation to the level of the lesion, the position of the patient, eventual presence of a corset, and lastly to contractures. The respiratory movements of the thorax had been studied and brought into evidence the paradoxical movements. Their work had also attempted to clarify the question of the reserve respiratory volume of patients with tetraplegia. The 
scapular muscles, certainly as far as this was concerned, played a rôle, and it was interesting to see how far their normal physiology could be modified under such conditions.

Silver, $\mathcal{F}$. (England) said that the cases reported were between nine months and five years after injury. At Dr. Guttmann's request, he had also measured patients immediately after transection of the cord and had found their vital capacity as low as $450 \mathrm{cc}$. Some of the patients had also a paralysed deltoid on one side, and in three cases where that happened the diaphragm was also paralysed, which accounted for the reduced vital capacity. It was very difficult to adjust the oxygen consumption in acute stages, as the patient tired quickly. With regard to Dr. Grossiord's electromyographic findings, Dr. Silver referred to studies which he was carrying out with Dr. Guttmann on auxiliary respiratory muscles, particularly the sternomastoid, and also on reflex activity of the intercostal muscles as a result of rhythmic pulmonary movements.

\title{
PENICILLIN G IN URINARY TRACT INFECTIONS
}

\author{
By H. L. Frankel and E. W. Colley \\ Stoke Mandeville Hospital (England)
}

Developments leading to the present position of Penicillin $G$ in urinary infection are reviewed. The sensitivity, in vitro, of 255 strains of Gram-negative urinary pathogens was determined up to a maximum concentration of $200 \mathrm{units} / \mathrm{ml}$. All strains of E. coli, nearly all strains of Providence and more than half the strains of Proteus mirabilis were inhibited by levels easily attainable in urine.

Of the 30 strains of Providence, 23 were biotype 2I and seven were biotype 27. The sensitivity of the 30 strains to Penicillin G, Penbritin, Broxil, Brocillin, Orbenin, Celbenin, tetracycline, streptomycin, Furadantin, Trimethoprim and Kanamycin was determined. Nearly all strains were sensitive to Penicillin $G$ and Penbritin, there was relative resistance to the other penicillins. All strains were sensitive to Trimethoprim and Kanamycin but only a few were sensitive to the remaining antibiotics.

Thirty-two paraplegic patients with urinary infection due to Providence were treated with intramuscular Penicillin G I,000,000 Units six hourly for six to Io days. At the end of treatment the urine was sterile in $2 \mathrm{I}$ patients, infected with other organisms in nine and Providence persisted in two. During the follow up (average 9.7 months) Providence recurred in five patients. At the end of follow up I 9 patients had sterile urine, six were infected with Providence, and seven infected with other pathogens.

It is concluded that Penicillin G is the drug of choice for Providence urinary infections and should be considered for $E$. coli infections which are resistant to other antibiotics. The relative cheapness of Penicillin G, compared with Penbritin and Kanamycin is mentioned.

\section{DISCUSSION}

Hardy, A. G. (England) congratulated Dr. Frankel on his concise paper and said he was glad that older methods were being revived and proving satisfactory.

Tribe, $C . R$. (England) asked how pathogenic was Providence. Now that the chief infection of a paraplegic was aerogenes, did penicillin have any effect on this? 
Frankel, $H$. (England) said that Providence was now very uncommon, as a result of treatment with penicillin. When this infection was reviewed by Dr. Milner from the Stoke Mandeville Pathology Department, he had found that it was responsible for 30 per cent. of urinary infection. Penicillin had no beneficial effect on aerogenes, both clinically and in laboratory tests. One advantage of penicillin was that it was relatively cheap. The alternative, Penbritin, was very expensive.

Annat, D. (England) drew attention to the great difference in price between Penicillin $\mathrm{G}$ and Penbritin. He felt that co-operation between clinicians and pharmacists was very important to reduce costs in prescribing drugs.

\title{
SUBDURAL INJECTION OF D-TUBO-CURARINE IN THE EARLY TREATMENT OF SPINAL CORD INJURIES
}

\author{
By Dr. C. V. Morpurgo \\ Istituto Ortopedico Gaetano Pini, Milan, Italy
}

IN accordance with observations made on animals by neurophysiologists, it is possible also to demonstrate in man that spinal shock is due to an excess of inhibitory circuits in the cord, when suddenly the facilitating influence from central parts of the nervous system are stopped. When the lesion of the spinal cord is complete it is impossible to elicit any reflex during the stage of spinal shock. The recovery from this condition is accomplished following gradual reduction of spinal inhibition below the level of the lesion and in man this takes place in more than 20 days.

The idea if using d-tubo-curarine in the treatment of spinal shock started from the experimental observation following intrathecal injection of this drug in the spinal as well as normal cat. The action is exerted on all types of inhibition including those controlling sensation and autonomic functions. Following these experiments we decided to try d-tubo-curarine during spinal shock in human subjects. Following intrathecal injection of I-2 mgms. there was always disappearance of the symptoms of spinal shock within I 5 minutes.

Dermographism reappears in the areas where it was absent. The return of the vascular reflex represents an important step in the therapy of traumatic shock. The intestinal tract regains tone and motility resulting in rapid disappearance of meteorism and a simple enema becomes efficient in causing evacuation. Many muscular, tendon and skin reflexes are restored and the threshold of electrical stimulation of the muscles is lowered. The impaired respiration when present becomes more efficient. In many patients it is possible to see a reduction of the level of anaesthesia. On a few occasions (three amongst 18 patients on whom this treatment was applied) the automatic function of the bladder starts after curare injection. The restored trophic function of the spinal cord facilitates the avoidance of hyperthermia, bed-sores and all metabolic disorders resulting from spinal shock.

In most subjects a single injection of curare has been sufficient to eliminate the state of spinal shock. In a few patients we noted a beneficial effect in repeating the injection after three to six and eight to twelve days. A good improvement of general and local conditions was also obtained within 20 days following spinal cord transection.

An oedematous spinal cord or the presence of hematorrhachis can account for a misleading result in the treatment. 
Curare probably acts on the central nervous system by inhibiting cholinesterases.

Several slides were shown to illustrate the paper.

\title{
DISCUSSION
}

Hardy, A. G. (England) said he found Dr. Morpurgo's paper fascinating. What dosage was used intrathecally and how long did its effect last?

Morpurgo, $V$. (Italy) replied that he injected I to $2 \mathrm{mg}$. in human beings who had a complete spinal shock. In cats, it was sufficient to inject I mg. The period of inhibition lasted up to two to three hours, but the spinal shock did not return.

Hardy, A. G. (England) asked how many times was the injection done.

Morpurgo, $V$. (Italy): Up to three times in I 5 days.

Hardy, A. G. (England) asked about the bladder and whether Dr. Morpurgo had been able to take out the catheter. Did reflex activity occur?

Morpurgo, $V$. (Italy) replied that this was difficult to answer. On one occasion, it had been possible to see spontaneous emptying of the bladder; in the other cases, he had not succeeded.

Hardy, $A$. G. (England) asked if there were any harm in injecting d-tubo-curarine.

Morpurgo, $V$. (Italy) replied that it was very safe.

Damanski, $M$. (England) asked at what level was the injection done.

Morpurgo, $V$. (Italy) said it was done as near as possible to the lesion or under the lesion. There were difficulties in injecting above the lesion.

Guttmann, L. (England) said that the injection of chemicals intrathecally was of great physiological interest, and he referred for instance to prostigmine which following intrathecal injection had a completely different action on the skeletal muscle as compared with that of intramuscular injection. Dr. Morpurgo's theory on spinal shock was indeed interesting, and it was quite astounding that d-tubo-curarine should abolish the symptoms of spinal shock. With regard to the cessation of spinal shock in animals, one had to be very careful with conclusions, as it was well known that the spinal shock usually disappeared very quickly. This was, of course, different in man, and Dr. Morpurgo's findings were quite astounding. As Dr. Morpurgo had pointed out that there was no harm in injecting d-tubo-curarine, no doubt he would follow up this and would report in due course whether these findings were confirmed or not.

\section{RENAL FUNCTION STUDIES IN PARAPLEGIC PATIENTS}

\author{
By J. R. Doggart and Dr. J. R. Silver \\ National Spinal Injuries Centre, Stoke Mandeville Hospital, Aylesbury, Bucks, England
}

THERE is still a high morbidity and mortality from urinary sepsis among paraplegics. During the First World War, 80 per cent. of the deaths among spinal injury cases were due to this cause. This very high initial mortality has ceased, as a result of the advances made in the management of these patients. Patients are living longer but they are still dying from chronic renal failure due to pyelonephritis, amyloidosis and hypertension.

There are numerous tests of renal function that can be performed, depending upon the particular function that is to be tested. The most popular involves the measurement of an endogenous material produced by the body, urea or creatinine. 
The most accurate involves the transf usion of an exogenous material, inulin. The performance of a clearance test for an endogenous substance appears to offer the best compromise between convenience and accuracy.

One hundred and forty endogenous Creatinine Clearances and 49 Urea Clearances were performed on 31 paraplegics in the early stages and 37 in the late stages following injury.

The serum creatinine was measured by the method of King and Wootton and the urine creatinine by the method of Bonsnes and Taussky. The blood and urine urea was determined by a diacetyl method.

The accuracy of clearance tests depends chiefly upon the care which is taken in emptying the bladder and collecting carefully timed and measured specimens of urine. Despite the fact that the patients have catheters installed throughout the tests, the presence of reflux can make it difficult to collect all the urine secreted by the kidneys. This source of error was reduced by collecting the urine over time intervals of $12-24$ hours in the Creatinine Clearance test.

The Creatinine and Urea Clearance were compared. It was found that while in the long term patients there was little to choose between these tests, in the immediate and early stages following paraplegia the creatinine clearance was superior, because as there was fluid retention in the initial stages the rate of urine secretion did not rise above $2 \mathrm{ml}$. per minute. At these rates of urine secretion the urea clearance is inaccurate whereas the creatinine clearance is still a reasonable measure of glomerular filtration.

It was found that the Creatinine Clearance was substantially normal within 24 hours of injury and that the level of the cord injury had no effect on the clearance.

In the old patients all the cases of renal failure were associated with low clearances.

The results were correlated with post-mortem findings and rectal biopsy reports. The patients who died immediately after injury to the spinal cord had normal kidneys; the patients in renal failure had a mixed picture of amyloidosis and pyelonephritis.

It was concluded that for clinical investigations the endogenous creatinine clearance was a satisfactory test of renal function and was easily applicable to the study of the renal function of paraplegic patients.

\section{DISCUSSION}

Guttmann, L. (England) remarked that there were two points of interest. Firstly, there was no difference whatsoever in the creatinine clearance between low lesions and high lesions, in which the sympathetic control is eliminated. Secondly, it was of interest that in elderly paraplegic patients the creatinine clearance in the acute stages was found to be low and remained so for a long time. The question arose whether this was due to a renal deficiency acquired before the spinal injury. 